\title{
Sistem Informasi Radar Cuaca Terintegrasi BMKG
}

\section{The Integrated Weather Radar Information System of BMKG}

\author{
Anantia Prakasa ${ }^{1, *}$, Fitria Dwi Utami ${ }^{2}$ \\ ${ }^{1,2}$ Program Studi S1 Teknik Telekomunikasi, \\ Fakultas Teknik Telekomunikasi dan Elektro, Institut Teknologi Telkom Purwokerto \\ Jl. D.I.Panjaitan no.128 Purwokerto, Jawa Tengah, Indonesia \\ 1,*Penulis korespondensi: anantia@ittelkom-pwt.ac.id, \\ 215101081@ittelkom-pwt.ac.id
}

Received on 11-06-2019, accepted on 27-07-2019, published on 01-08-2019

Abstrak

Badan Meteorologi, Klimatologi dan Geofisika (BMKG) adalah badan pemerintah yang dilindungi Undang-Undang yang bertanggung jawab menyediakan data dan informasi cuaca di wilayah kedaulatan Indonesia. Hingga tahun 2017 BMKG baru memiliki 41 radar cuaca yang tersebar di seluruh wilayah Indonesia. Tersebarnya lokasi radar cuaca ini membuat pengelolaan data dan informasi radar cuaca bersifat sektoral, parsial, dan terpecah-pecah serta kurang berdaya guna kemanfaatannya bagi masyarakat banyak. Untuk itu BMKG melakukan terobosan dengan membuat "dokumen cetak biru" yang memperlihatkan sistem integrasi radar cuaca di seluruh Indonesia pada masa mendatang termasuk penambahan radar cuaca baru di lokasi yang belum terliput. Perencanaan sistem integrasi ini mulai dilakukan pada 21 radar cuaca existing di berbagai lokasi di Indonesia dengan cara menghubungkan radar cuaca tersebut pada jaringan telekomunikasi. Dengan terhubungnya 21 radar cuaca tersebut pada jaringan telekomunikasi maka data radar cuaca bisa dikendalikan dan dimonitor dari jarak jauh selain kesehatan radar tersebut juga bisa dipantau. Lebih daripada itu, data dan informasi cuaca bisa didiseminasi dan diakses setiap saat. Selain itu, data \& informasi cuaca tersebut dapat disimpan untuk keperluan peramalan dan analisis cuaca pada masa mendatang. Data dan Informasi radar cuaca tersebut antara lain: presipitasi, arah dan kecepatan angin, deteksi pergerakan hujan, intensitas hujan, informasi peringatan dini seperti alerting dan warning cuaca sekitar bandara / pelabuhan.

Keywords: Informasi radar cuaca, Parsial, Radar cuaca, Sektoral, Sistem integrasi radar cuaca.

Abstract

The Meteorology, Climatology, and Geophysics Agency (BMKG) is a government agency protected by law that is responsible for providing weather data and information in Indonesia's sovereign territory. Until 2017, the BMKG only had 41 weather radars spread throughout Indonesia. The spread of weather radar locations makes the management of weather radar data and information sectoral partial, fragmented, and less beneficial for the community. For this reason, BMKG made a breakthrough by making a "blueprint document" showing the integrated weather radar system throughout Indonesia in the future, including the addition of new weather radar in locations that have not been covered. Planning for this integrated system has begun to be carried out on 21 existing weather radars in various locations in Indonesia by connecting these weather radars to the telecommunications network. By connecting the 21 weather radars to the telecommunications network, the weather radar data can be controlled and monitored remotely, besides the health of 


\begin{abstract}
the radar can also be monitored. Moreover, weather data and information can be disseminated and accessed anytime. In addition, the weather data $\&$ information can be stored for forecasting and weather analysis purposes in the future. The weather radar data and information include precipitation, wind direction \& speed, detection of rain movement, rain intensity, early warning information such as alerting and warning weather around airports/ports.
\end{abstract}

Keywords: Partial, Sectoral, Weather radars, Weather radar information, Weather radar integration system,

\title{
I. Pendahuluan
}

Indonesia yang terletak di antara dua benua yaitu Asia dan Australia, dua lautan dunia yaitu Lautan Pasifik dan Lautan Indonesia, serta berpenduduk lebih dari 261 (dua ratus enam puluh satu) juta jiwa lebih [1] (data statistik BPS tahun 2018) mempunyai wilayah daratan dan lautan yang besar dan luas. Kebutuhan akan informasi tentang kondisi cuaca, baik lokal maupun regional, menjadi mengemuka seiring pertumbuhan ekonomi suatu wilayah kedaulatan NKRI, utamanya yang berhubungan dengan peramalan dan mitigasi cuaca, iklim, dan kebencanaan untuk transportasi, pertanian serta industri.

Salah satu badan otoritas yang disahkan undang-undang dan bertanggung jawab mengelola data dan informasi tentang cuaca, iklim, dan kebencanaan di Indonesia adalah Badan Meteorologi, Klimatologi dan Geofisika (BMKG). Hingga tahun 2017, BMKG telah memiliki 41 radar cuaca yang tersebar di wilayah Indonesia mulai dari wilayah Aceh sampai Papua. 41 lokasi radar cuaca tersebut terdiri dari 15 Radar Gematronik, 20 Radar EEC, 5 Radar Baron, dan 1 Radar Vaisala. Gambar 1 memperlihatkan cakupan (coverage) dari stasiun radar cuaca yang dioperasikan oleh BMKG [2] beserta rencana penambahan stasiun radar cuaca di beberapa daerah lain di seluruh wilayah Indonesia dalam rentang waktu 2015 -2024. Diharapkan dengan jumlah radar cuaca nantinya tidak kurang dari 60 stasiun radar cuaca dengan jarak antara radar cuaca sekitar $150 \mathrm{Km}$ rata-rata maka diharapkan akan dapat meliput cuaca, iklim dan kebencanaan diseluruh Indonesia secara bersamaan (simultaneously).

Namun sampai saat ini pengelolaan data dan informasi tentang cuaca tersebut masih bersifat lokal, sektoral/parsial, dan belum simultan, sehingga perlu adanya upaya pengintegrasian dalam pola pengembangan yang baru, terpadu, dan lintas sektoral.

Dalam rangka pengintegrasian tersebut BMKG membuat "Cetak Biru (Blue Print) teknologi Informasi BMKG tahun 2015 - 2019” [3] yang menetapkan upaya-upaya yang sistematis dan berkesinambungan untuk pengintegrasian dalam pola pengembangan dan dukungan kebijakan teknologi informasi yang baru, terpadu dan lintas sektoral. Diharapkan dengan implementasi "Cetak Biru" yang berkesinambungan tersebut maka penggunaan radar cuaca akan lebih mendukung pembangunan nasional dan mendukung keselamatan masyarakat (untuk peramalan cuaca harian maupun early warning cuaca ekstrim, iklim maupun bencana alam yang bertujuan membantu meningkatkan keselamatan transportasi).

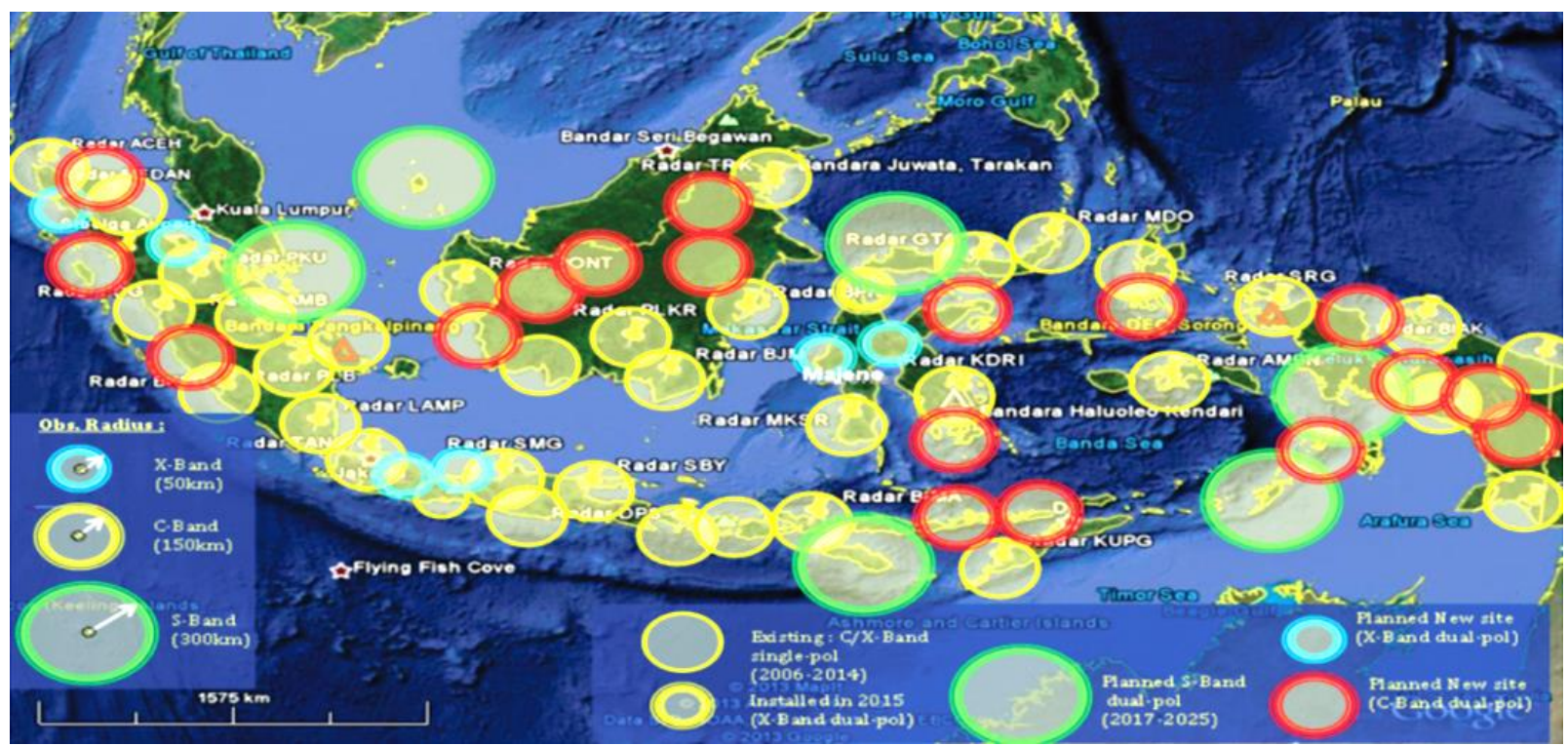


Gambar 1 Peta Lokasi radar cuaca BMKG pada tahun 2006 - 2015 dan rencana instalasi tahun 2015 - 2024

Membandingkan dengan sistem radar cuaca terintegrasi yang sudah beroperasi lebih dahulu di Amerika bernama NEXRAD [4] ataupun OPERA yang dioperasikan negara-negara di Eropa [5], maka PT. LEN mencoba menjembatani agar sistem integrasi radar cuaca dan informasinya, yang sekarang dioperasikan BMKG di berbagai wilayah Indonesia, akan bisa lebih berdaya guna, baik akses serta pemanfaatan jenis data dan informasinya bagi setiap lapisan masyarakat maupun sisi kemudahan operasi serta pemeliharaannya oleh BMKG.

Dari 21 (dua puluh satu) lokasi radar cuaca yang sudah sudah terpasang \& beroperasi (existing) akan diintegrasikan antara lain yaitu radar Medan, radar Pekanbaru, radar Lampung, radar Tangerang, radar Balikpapan, radar Tarakan, radar Banjarmasin, radar Kendari, radar Ambon, radar Palembang, radar Padang, radar Bengkulu, radar Jambi, radar Surabaya, radar Lombok, radar Palangkaraya, radar Sintang, radar Nias, radar Yogyakarta, radar Kupang, dan radar Semarang. Pengintegrasian radar cuaca tersebut meliputi konektivitas setiap radar cuaca dalam satu sistem jaringan radar dan juga penyatuan data radar cuaca untuk melihat profil cuaca utuh Indonesia secara bersamaan (concurrently).

Kebanyakan radar cuaca yang akan diintegrasikan tersebut beroperasi pada jalur $\mathrm{C}$ ( $C$-Band); dan di beberapa daerah digunakan radar cuaca jalur X (X-Band); alasannya mempertimbangkan adanya perbedaan kebutuhan tentang karakteristik meteorologi dan klimatologi yang cukup signifikan, misalnya kemampuan mendeteksi cuaca yang lebih baik terutama pada partikel-partikel air didalam awan. Radar cuaca yang beroperasi pada jalur $\mathrm{C}(C$ Band) dengan polarisasi tunggal (single polarization) mempunyai jangkauan maksimum hingga radius $150 \mathrm{Km}-$ $240 \mathrm{Km}$, sedangkan radar cuaca jalur X (X-Band) polarisasi ganda (dual polarization) mempunyai jangkauan radius $50 \mathrm{Km}-60 \mathrm{Km}$ [2].

Dari bermacam-macam radar cuaca yang dioperasikan BMKG maka ada 4 (empat) tipe radar cuaca yang digunakan berdasarkan pabrikan atau produsennya. Dari tiap-tiap radar cuaca dari gambar 1: masing-masing mempunyai fitur (feature) dan format data radar yang berbeda dan beragam, dan juga software bawaan radar yang berbeda pula. Tiap format data radar tersebut hanya dapat diolah menggunakan perangkat lunak (software) yang berasal dari pabrikan (produsen) radar tersebut; dan beberapa hanya dapat diolah oleh perangkat lunak yang ter-install di lokasi radar dan stasiun BMKG setempat dikarenakan kendala lisensi.

Tabel 1 Radar Cuaca yang dioperasikan BMKG dan akan di integrasikan

\begin{tabular}{|c|c|c|c|}
\hline Nama Radar & Frekuensi Kerja & Pabrikan & Software Bawaan Radar \\
\hline Radar Gematronik & C-Band & Selex ES GmbH & Rainbow \\
\hline Radar EEC & C-Band atau X-Band & EEC $*$ & Frog \\
\hline Radar Baron & C-Band & Baron & IRIS \\
\hline Radar Vaisala & C-Band & Vaisala & Edge \\
\hline
\end{tabular}

*EEC:Enterprise Electronic Corporation

Radar cuaca menghasilkan data / informasi secara berkesinambungan (continue) setiap 10 menit sekali [2] (setting observation interval bervariasi antara 5 menit 10 menit) [6] dan data tersebut akan tersimpan pada tempat penyimpanan lokal di lokasi radar. Tingginya frekuensi pengamatan oleh radar menyebabkan data radar cuaca yang disimpan berukuran cukup besar dan bervariasi - bergantung pada jenis produk radar. Kemudian data tersebut akan di transfer dan di-backup ke stasiun BMKG daerah atau BMKG pusat. Bila proses transfer tidak terjadi dan atau tempat penyimpanan data di lokasi radar sudah penuh, maka data radar yang baru akan menggantikan data yang lama (over-written).

Selain terintegrasinya radar cuaca yang dioperasikan BMKG selanjutnya adalah cara mendiseminasikan dan mendistribusikan data/informasi yang tersedia [3]. Dengan adanya teknologi internet dimungkinkan penyediaan data dan informasi yang dibutuhkan oleh masyarakat dapat di salurkan sesuai klasifikasi dan kepentingannya masing-masing. Struktur Sistem Aplikasi yang digunakan untuk mendiseminasikan dan mendistribusikan tersebut mempunyai struktur terlihat pada gambar dibawah ini. 


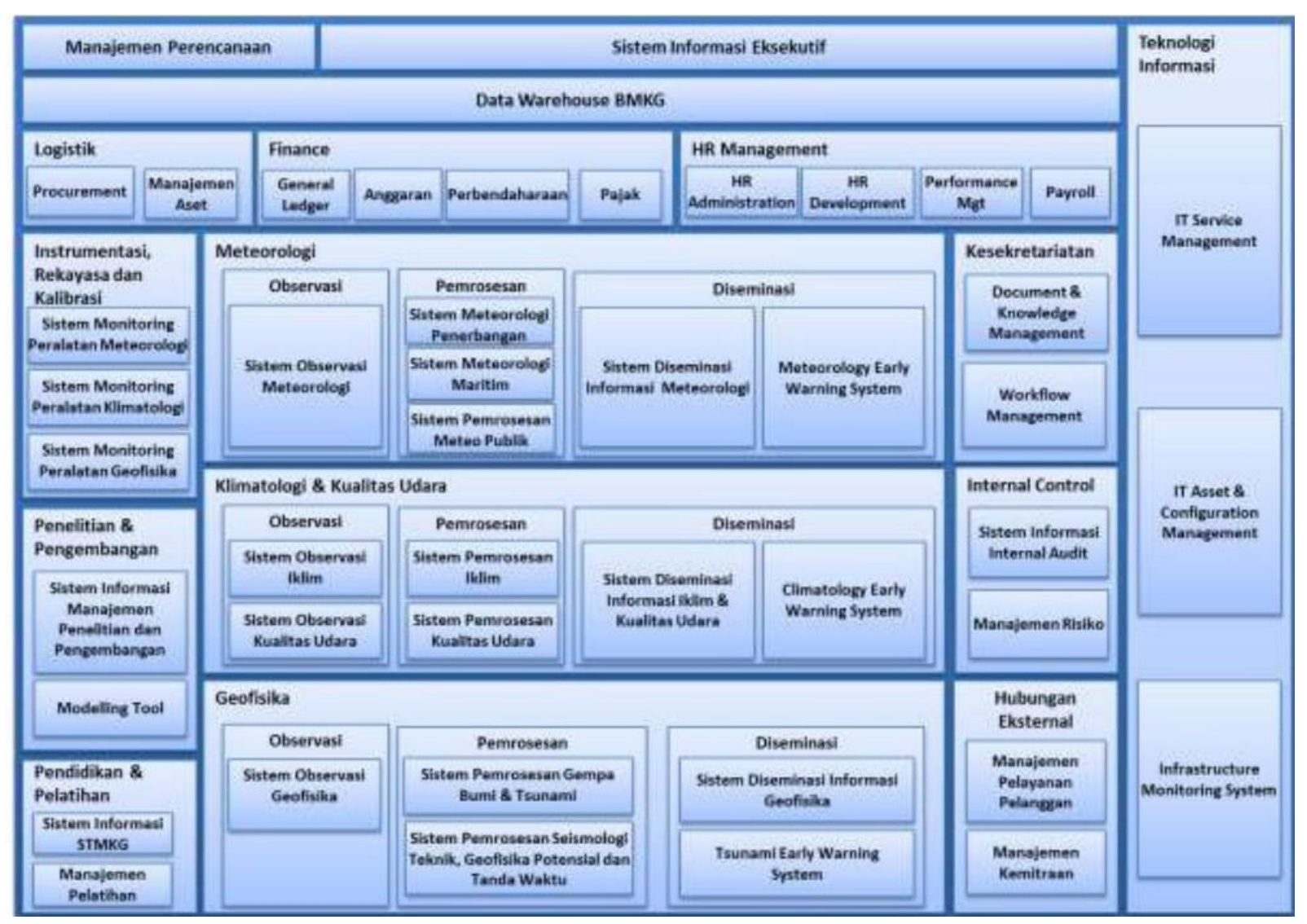

Gambar 2 Struktur Sistem Aplikasi keseluruhan BMKG [3]

\section{TINJAUAn PUStaka}

Sistem radar cuaca didunia sekarang ini bekerja pada rentang frekuensi di jalur L ( $L$-Band) hingga jalur-X ( $X$ $B a n d)$ dan alokasi ini diatur oleh ITU, ICAO dan IMO bersama-sama industri yang terlibat misalnya pabrikan radar. Tabel 1 berikut memperlihatkan beberapa kelebihan / keunggulan radar cuaca yang bekerja pada masingmasing jalur (Band) [7].

Tabel 2 Jalur frekuensi radar cuaca dan panjang gelombang

\begin{tabular}{|c|c|c|c|}
\hline Band Designation & Frekuensi Kerja Radar & Panjang Gelombang & Keunggulan \\
\hline VHF & $30-300 \mathrm{MHz}$ & $10-1 \mathrm{~m}$ & \\
\hline UHF & $300-1000 \mathrm{MHz}$ & $1-0.3 \mathrm{~m}$ & Deteksi Turbulensi Udara \\
\hline $\mathrm{L}$ & $1-2 \mathrm{GHz}$ & $30-15 \mathrm{~cm}$ & Observasi Jarak Jauh \\
\hline $\mathrm{S}$ & $2-4 \mathrm{GHz}$ & $15-8 \mathrm{~cm}$ & Cuaca Jarak Dekat \\
\hline $\mathrm{C}$ & $4-8 \mathrm{GHz}$ & $8-4 \mathrm{~cm}$ & Partikel-pertikel kecil \\
\hline $\mathrm{X}$ & $8-12 \mathrm{GHz}$ & $4-2.5 \mathrm{~cm}$ & \\
\hline
\end{tabular}

Secara umum prinsip kerja radar cuaca bekerja berdasar efek Doppler [7] yang artinya proses pendeteksian suatu objek oleh gelombang radio berdasarkan selisih frekuensi pantul $f_{1}$ dari pergeseran frekuensi kerja radar $f_{0}$ akibat pergerakan objek tersebut. Semakin banyak objek tersebut dan bergerak cepat maka efek Doppler yang dihasilkan akan semakin besar. Efek Doppler inilah yang akan dikonversi menjadi redaman curah hujan dalam bentuk kodekode warna. 


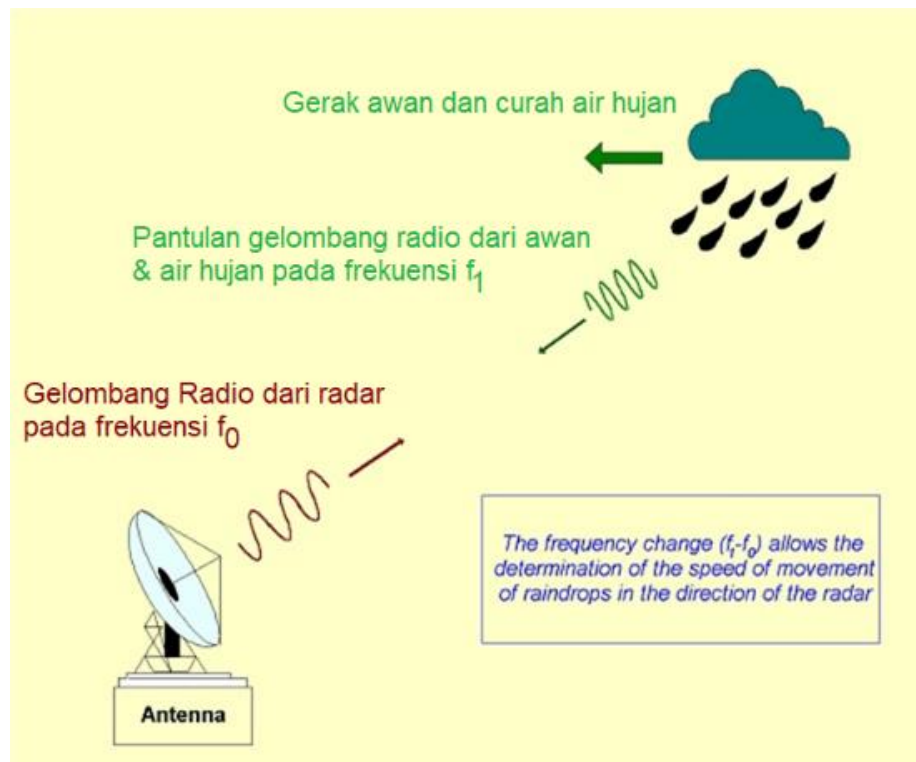

Gambar 3 Prinsip Kerja Radar Cuaca berdasarkan pergeseran frekuensi atau efek Doppler

Secara umum radar cuaca yang dioperasikan BMKG kebanyakan masih menggunakan teknologi pemancar magnetron ataupun klystron . Tipikal blok diagram dari radar cuaca polarisasi tunggal (single polarization) dan polarisasi ganda (dual polarization) yang menggunakan pamancar magnetron ditampilkan berikut ini.

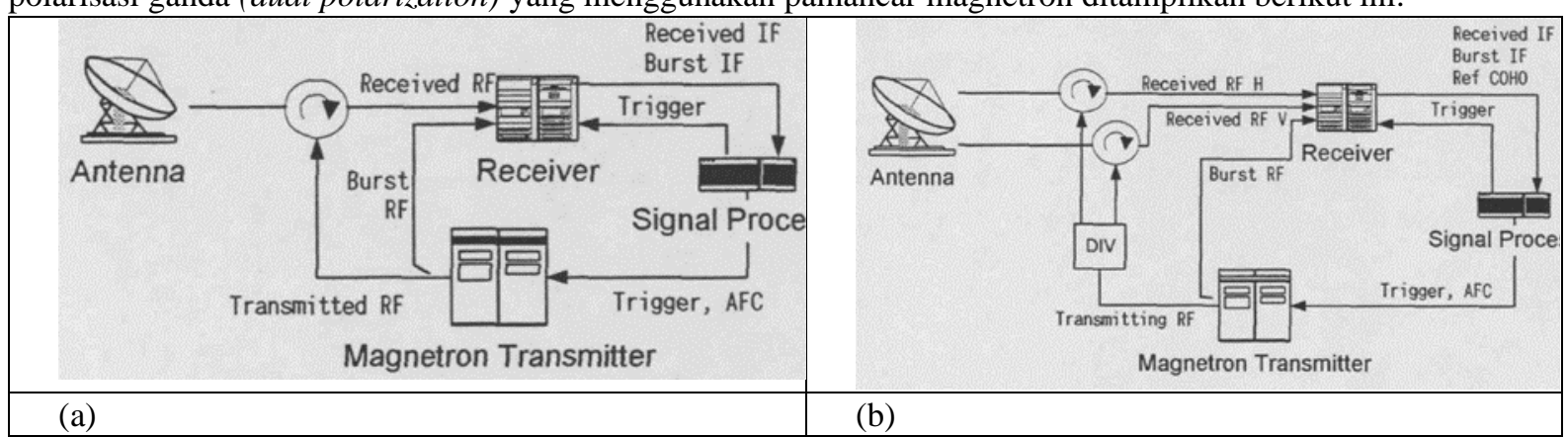

Gambar 4 Tipikal Sistem Radar Cuaca Polarisasi Tunggal (a) dan ganda (b) menggunakan Magnetron [8]

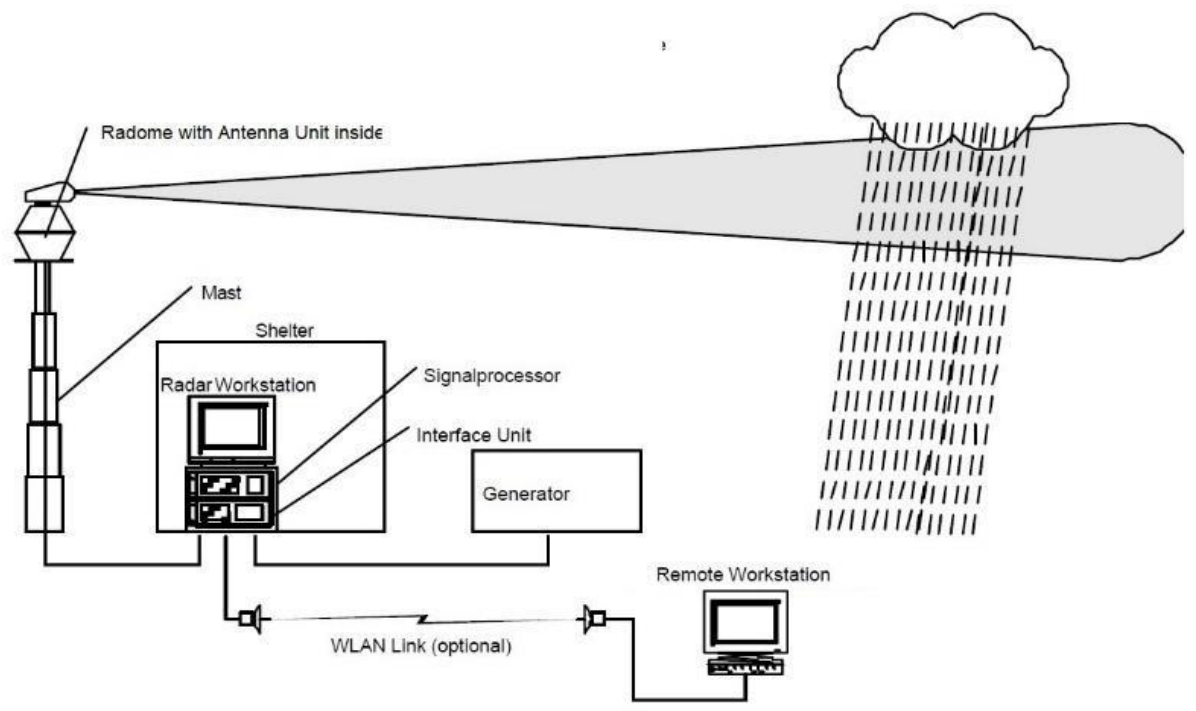

Gambar 5 Detil Sistem Radar Cuaca Magnetron Polarisasi Tunggal [9] 
Untuk mengintegrasikan radar cuaca pada jaringan telekomunikasi maka perlu diperhatikan infrastruktur Teknologi Informasi (TI) target beserta arsitekturnya. Arsitektur infrastruktur Teknologi Informasi (TI) adalah teknologi (hardware/software) untuk memberikan akses pengguna (aparatur dan masyarakat) kepada arsitektur aplikasi, arsitektur integrasi dan arsitektur informasi sehingga arsitektur infrastruktur TI bisa berjalan untuk mendukung fungsi-fungsi BMKG dalam melayani masyarakat, aparatur maupun sektor pemerintahan lainnya. Gambar diatas memperlihatkan bagaimana suatu sistem radar cuaca terhubungkan pada remote workstation untuk mentranfer data/informasi cuaca ke BMKG pusat dengan opsi media WLAN Link.

Dalam implementasinya, komponen-komponen arsitektur infrastruktur TI terdiri dari server atau kumpulan server, LAN/WAN, Data Center, dan Cloud Computing.

Server atau kumpulan server memiliki fungsi untuk memberikan layanan tertentu untuk mengelola sumber daya tertentu di dalam suatu jaringan, kebutuhan server-server dirancang agar selaras dengan kebutuhan BMKG. Server yang akan/sedang [3] dibuat dan terus dikembangkan adalah:

1. Server Aplikasi Instrumentasi Rekayasa dan Kalibrasi (IRK) dan Observasi: adalah server yang digunakan untuk IRK peralatan meterologi, klimatologi, dan kualitas udara dan IRK peralatan geofisika.

2. Server Aplikasi Pemrosesan: adalah server yang digunakan melakukan pengolahan data meterologi penerbangan dan maritim, meterologi publik, iklim agroklimat, dan maritim, perubahan iklim, dan kualitas udara, gempa bumi, dan tsunami, seismologi teknik, geofisika potensial, dan tanda waktu.

3. Server Aplikasi Diseminasi adalah server yang digunakan untuk mendiseminasikan / mendistribusian informasi meteorologi, peringatan dini meteorologi, diseminasi info klimatologi, peringatan dini klimatologi, diseminasi info geofisika dan peringatan dini geofisika.

4. Server Aplikasi Pelayanan adalah server untuk layanan yang dapat diakes oleh masyarakat misalnya portal BMKG.

5. Server Aplikasi Eksekutif adalah server aplikasi khusus untuk keperluan pengambilan keputusan.

6. Server Aplikasi System Management adalah server yang digunakan untuk pengelolaan sistem di BMKG secara keseluruhan, misalnya pengelolaan jaringan, gedung dan lainnya.

Secara teknik fungsi-fungsi server tersebut diatas tidak mengharuskan dalam suatu fisik komputer server tersendiri melainkan dapat melalui sebuah kumpulan Virtual Machine (VM).

Untuk teknologi jaringan komunikasi data yang diterapkan adalah LAN dan WAN. Dengan prinsip redundancy yang akan diimplementasikan dalam setiap layanan komunikasi data diharapkan tingkat ketersediaan (level availability) layanan antar jaringan bisa diperoleh. Opsi pilihan jaringan komunikasi data untuk mendiseminasi data / informasi cuaca antara lain serat optik, MPLS, Metro Ethernet dan Digital Video Broadcasting (DVB).

\section{Metode Penelitian}

\section{A. Pengintegrasian Radar Cuaca}

Pengintegrasian radar cuaca BMKG tidak lepas juga dari pengembangan infrastruktur jaringan Telekomunikasi dan Informasi (TI) pada masing-masing kantor daerah dan pusat yang bertujuan melayani pengguna dalam mengakses data dan informasi secara cepat dan mudah. Pemilahan layanan dalam sebuah sistem perlu dilakukan secara tepat sehingga infrastruktur yang dikembangkan dapat memberikan manfaat secara optimal. Arsitektur jaringan TI yang dibuat difokuskan pada 3 lapisan fungsional area atau lapisan jaringan (layer) dengan model hirarki yang secara sederhananya masing-masing layer menyediakan layanan yang berbeda bagi end-station dan server sbb:

1. Lapisan Inti (Core layer), Lapisan Inti bertanggung jawab untuk meneruskan lalu lintas data (forwarding) secara cepat dan handal. Pada lapisan inti prosesnya berupa high speed switching yang mendukung teknologi Gigabit Ethernet.

2. Lapisan Distribusi (Distribution layer), Lapisan distribusi disebut juga layer workgroup yang menerapkan titik komunikasi antara lapisan akses dan lapisan inti. Pada lapisan distribusi prosesnya adalah proses routing yang lebih berdasar pada policy-based connectivity. Pada layer inilah proses routing untuk aplikasi, common data base dan VLAN dapat dilakukan. 
3. Lapisan Akses (Access layer), Lapisan ini disebut layer desktop. Fungsi utamanya adalah menjadi sarana bagi suatu titik yang ingin berhubungan dengan jaringan luar. Pada lapisan akses proses yang terjadi yaitu berupa proses local switching satuan-satuan kerja atau Unit Pelaksana Teknis (UPT) yang ada di BMKG.

Koneksi internet dari semua UPT dan Balai Besar harus melewati proxy server dengan tingkat keamanan yang dikendalikan terpusat. Pada masa mendatang penggunaan DVB sebagai media jalur komunikasi untuk memperkuat infrastruktur jaringan WAN BMKG akan dipertimbangkan mengingat faktor-faktor ssebagai berikut:

1. Latency yang lebih baik dan bandwidth yang lebih kecil.

2. Mempunyai kemampuan untuk menyebarkan data/informasi dari satu pengirim ke banyak pengirim sehingga terjaminnya pengiriman data-data sampai ke kantor UPT BMKG.

3. Konektivitas jaringan untuk pengumpulan data dan informasi dari setiap kantor UPT BMKG lebih efisien.

Hal ini berbeda jika dilakukan menggunakan MPLS maka data/informasi dari setiap stasiun radar cuaca atau UPT harus dikirimkan satu per satu dari pengirim ke satu penerima.

Manfaat dari rancangan topologi jaringan model hirarki [3] [10] antara lain sebagai berikut:

a. Skalabilitas (scalability): jaringan hirarki dapat dengan mudah dikembangkan lebih lanjut suatu saat jika dibutuhkan.

b. Ketersediaan (availability): saat jaringan akan dikembangkan lebih lanjut, ketersediaan jaringan menjadi hal yang sangat penting.

c. Kinerja (performance): jaringan hirarki yang dibuat dengan baik dapat mencapai wire-speed terdekat di antara seluruh perangkat jaringan.

d. Keamanan (security): switch-switch pada lapisan akses layer dikonfigurasi untuk lebih mengontol perangkat yang terhubungan ke jaringan

e. Kemudahan pengelolaan (manageability): konsistensi antar perangkat switch pada masing-masing layer membuat pengelolaan lebih sederhana.

f. Kemudahan perawatan (maintainability): karena modularitas dan skalabilitas yang dimiliki maka pemeliharaan jaringan hirarki akan lebih mudah dilakukan.

g. Redundansi (redundancy): jaringan hirarki menerapkan redundansi medium komunikasi untuk menjaga ketersediaan data dan informasi tanpa putus/jeda.

Untuk mengintegrasikan radar cuaca pada jaringan telekomunikasi maka ditempatkanlah perangkat-perangkat baru diantara radar dan jaringan telekomunikasi tersebut. Dengan penambahan perangkat baru tersebut topologi jaringan radar cuaca disetiap lokasi tipikalnya akan tampak seperti pada gambar berikut .



Gambar 6 Topologi Sistem Radar Ambon agar terintegrasi pada jaringan VSAT (Tipikal)

Pada topologi jaringan radar Ambon digunakan VSAT untuk mengirim (transfer) data dari server radar ke BMKG. Jaringan radar Ambon terdiri dari sistem radar cuaca yang dikendalikan oleh server radar; dalam server ini informasi atau data dari radar cuaca disimpan dan diolah sebelum dikirimkan ke storage-server berikutnya. 
Kemudian data dari storage-server tadi di-switch dengan LDM (Local Data Manager) server. LDM server ini adalah seperangkat program untuk mendistribusikan data bumi atmosfer plus data cuaca ke user (peneliti atau teknisi). Sistem ini fokus dengan melewatkan, menerima, dan mengelola produk data yang diakses melalui teknologi berbasis event (push) melalui internet. Setelah data diolah oleh LDM server, kemudian di-switch untuk dikirimkan ke server BMKG pusat untuk ditampilkan di komputer user. Tampilannya akan berupa data cuaca dan klimatologi beserta beserta intensitas curah hujan di daerah Ambon.

Secara nasional, maka setiap radar cuaca di berbagai wilayah Indonesia akan terhubung nantinya pada sistem jaringan radar seperti tampak pada gambar 11 .

Untuk mengintegrasikan setiap radar cuaca pada satu common platform yang sama maka perlu disepakati terlebih dahulu informasi dan raw-data apa saja yang akan di pertukarkan pada setiap node. Informasi tersebut bukan hanya parameter-parameter radar beserta data-datanya tetapi terkandung juga informasi waktu dan tempat pada setiap raw-data. Dari tabel 1 juga diketahui antar muka (interface) tiap-tiap radar cuaca tersebut mempunyai antar-muka, format data, karakteristik dan spesifikasi data yang beragam. Untuk itu diperlukan konversi agar bisa terdapat kesesuaian data dan informasi pada common bus yang sama. Agar lebih ringkas maka konversi dari setiap data radar cuaca dilakukan secara lokal, artinya peng-konversian-dilakukan disetiap stasiun radar sebelum dikirimkan ke sistem jaringan radar; hal ini dilakukan untuk menghemat bandwidth - walaupun begitu waktu yang dibutuhkan untuk mengkonversi akan memberikan waktu tambahan diluar waktu pengiriman dan pemrosesan oleh radarnya sendiri. Untuk itu maka informasi cuaca dari yang akan di share dari tiap-tiap radar cuaca adalah parameter-parameter utama saja sedangkan fitur dengan parameter spesifik tiap-tiap hanya akan ditampilkan di lokal saja.

Informasi-informasi cuaca disisi client dapat dilihat dengan bantuan browser SmartWX atau browser yang setara, sedangkan parameter-parameter utama (major information parameters) yang akan ditampilkan sebagai berikut: karakteristik dan tipe presipitasi, arah dan kecepatan angin, deteksi pergerakan hujan, intensitas hujan, akumulasi jumlah curah hujan, informasi peringatan dini, kondisi cuaca disekitar bandara, informasi dalam file format animasi.

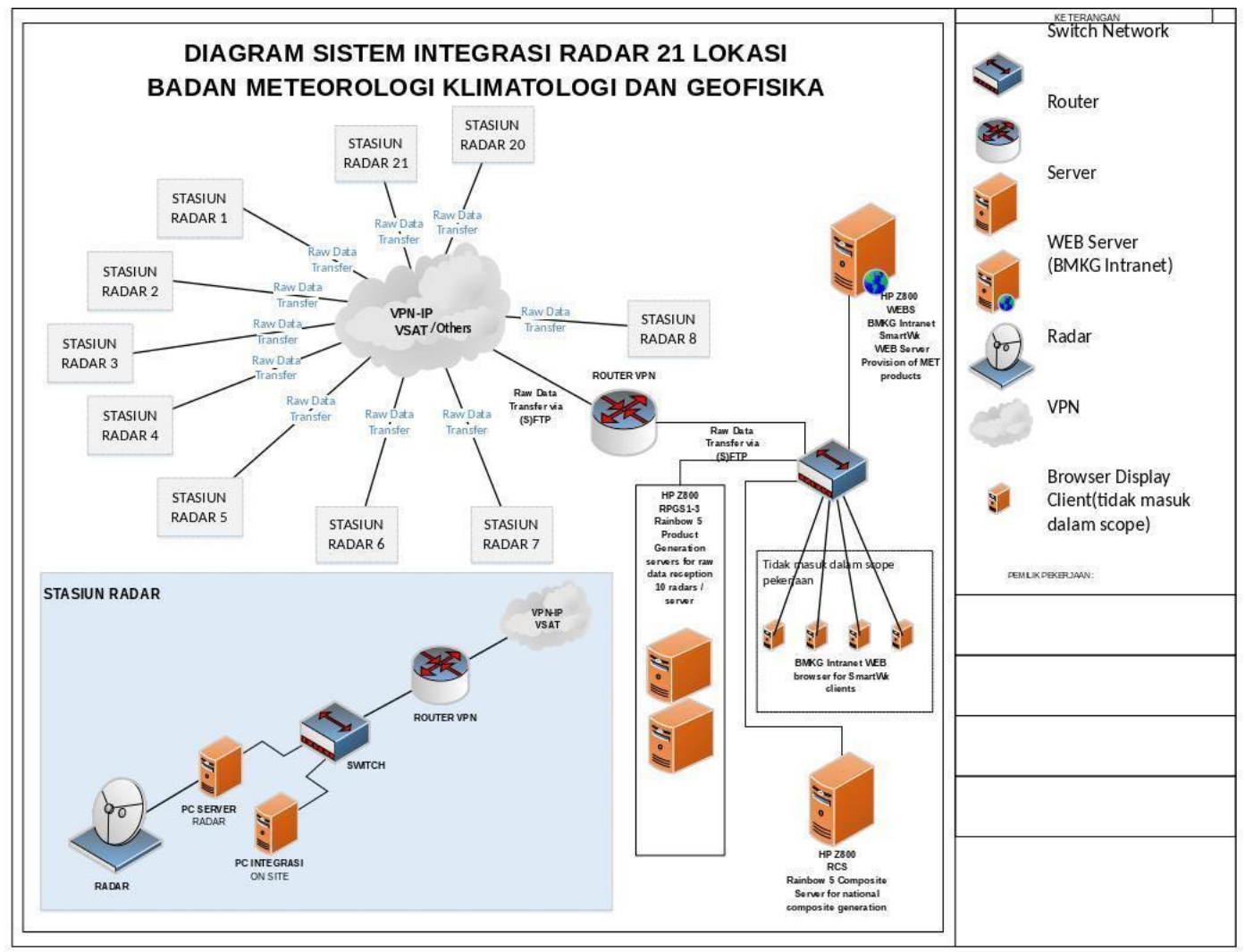

Gambar 7 Blok Diagram Sistem Integrasi Radar 21 lokasi yang dioperasikan BMKG 
Gambar berikut adalah gambar salah satu bagian User Interface dari browser SmartWX yang sudah dipakai dan masih terus dikembangkan; tampak tampilan kondisi cuaca diarea Batam / Kepulauan Riau dan di bandingkan dengan ukuran daratan di area tersebut (superimposed). Pada jendela yang sama dimungkinkan untuk mengatur settings dan tools yang diperlukan. Browser ini akan digunakan sebagai antar muka yang bersifat centralized untuk mengelola radar cuaca diseluruh Indonesia, tanpa peduli jenis radar cuaca apapun.



Layout of the SmartWx browser client

Gambar 8 Contoh User Interface(UI) SmartWX browser untuk cuaca dalam peta geografis 


\section{HaSil Dan ANALISIS}

Hasil penelitian memperlihatkan bahwa dokumen "cetak biru" sebagai sebuah rujukan dan roadmap sistem jaringan radar cuaca di Indonesia sudah bisa dilihat. Situs internet BMKG yang menyediakan layanan cuaca, klimatologi dan kegempaan bisa diakses oleh masyarakat baik menggunakan gawai berbasis Android maupun komputer pada umumnya. Berikut adalah citra radar yang dibuat berdasarkan seluruh stasiun radar cuaca di Indonesia.

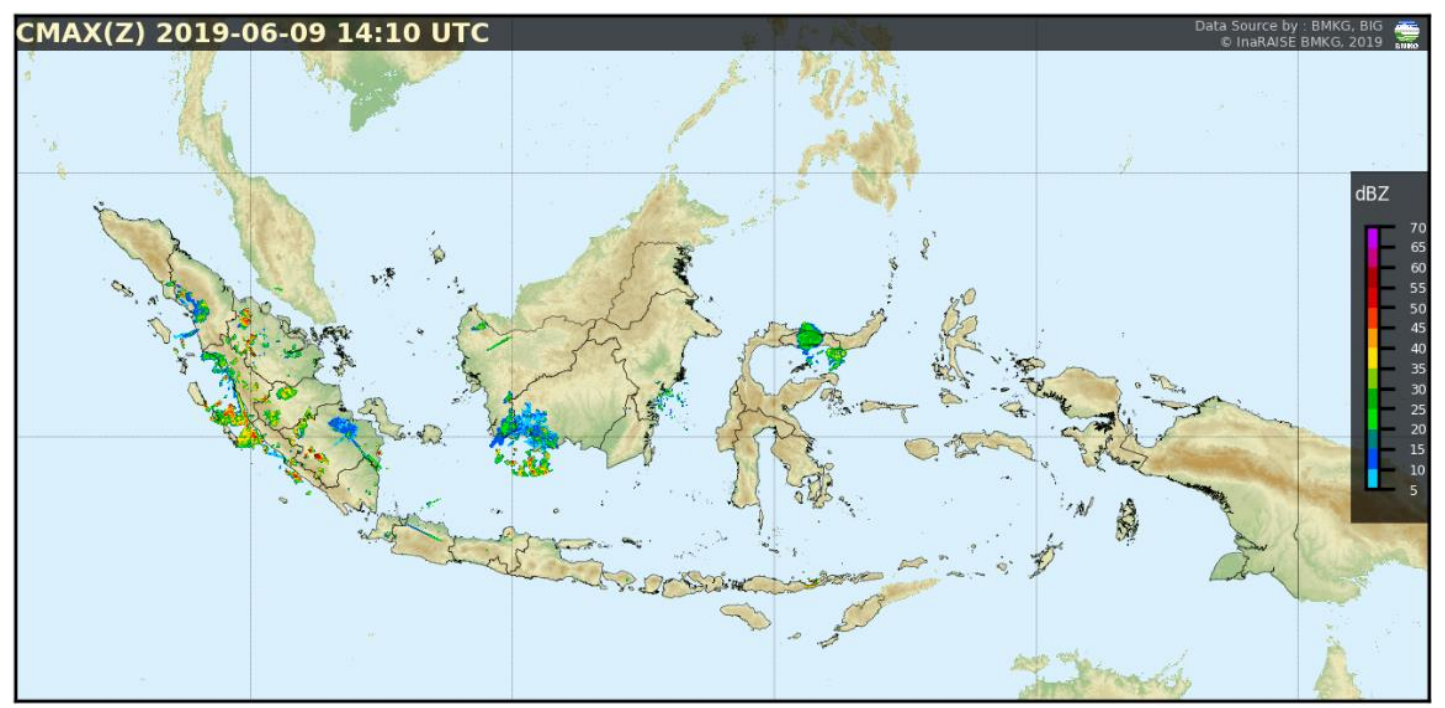

Gambar 9 Citra radar cuaca Indonesia status tanggal 09 Juni 2019 pukul 14:00 [11]

Dari gambar 1 juga dapat terlihat bahwa pemasangan radar cuaca dimaksudkan untuk mengetahui cuaca didaratan dan sekitar lepas pantai saja. Sedangkan untuk mengetahui cuaca di daerah laut lepas, informasi cuacanya dilakukan dengan menggunakan radar satelit. Gambar berikut dibawah ini memperlihatkan cuaca di waktu yang sama dengan gambar 16.

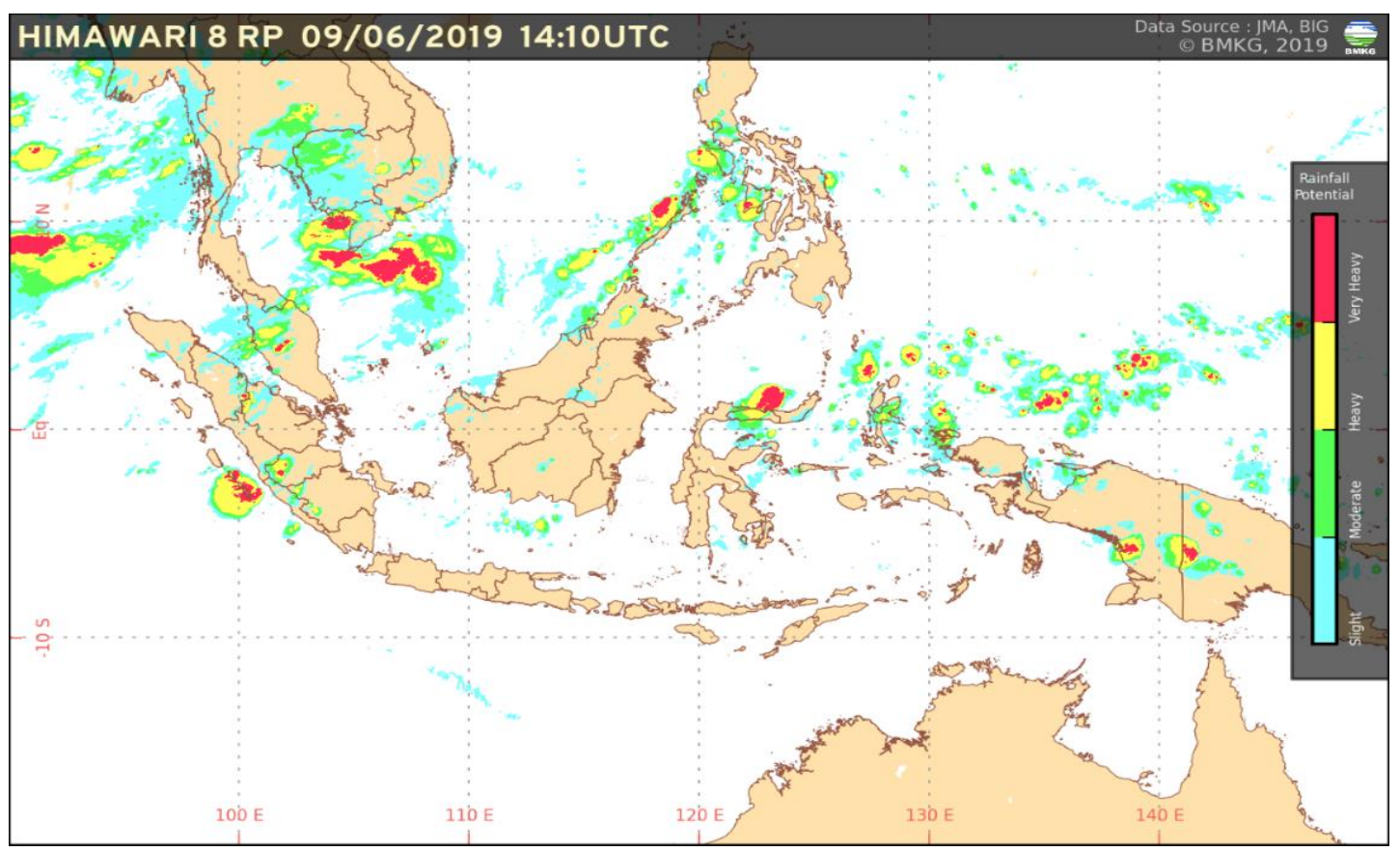

Gambar 10 Citra radar satelit Himawari 8 [12] 


\section{KeSIMPULAN}

Berdasarkan hasil penelitian yang telah dilaksanakan, diperoleh kesimpulan bahwa jumlah radar cuaca yang diperlukan untuk mengetahui cuaca di wilayah daratan Indonesia masih sangat kurang. Juga tahapan-tahapan untuk mengintegrasikan radar cuaca di Indonesia agar bisa mengetahui cuaca di Indonesia secara keseluruhan dan bersamaan (simultaneously) ternyata membutuhkan waktu yang lama. Hal ini berkaitan dengan perencanaan pembelian, pemasangan, pengujian, pengintegrasian dan kalibrasi. Diperkirakan baru pada tahun 2024 seluruh wilayah daratan Indonesia bisa terliput radar cuaca sehingga kondisi lengkap cuaca Indonesia bisa diketahui.

\section{ACKNOWLEDGMENT}

Melalui kesempatan ini, penulis mengucapkan terima kasih kepada Tim JTECE, yang telah memberikan kesempatan untuk dapat mempublikasikan tulisan ini. Juga penulis berterima kasih kepada seluruh civitas Institut Teknologi Telkom Purwokerto umumnya dan S1 Teknik Telekomunikasi pada khususnya, yang telah mendukung dalam menyelesaikan penelitian ini.

\section{REFERENCES}

[1] B. P. S. (BPS) Indonesia, “Indonesia Statistical Yearbook of Indonesia 2018,” 2019.

[2] M. Weather, R. Format, and D. Processing, "Pengolahan Multi Data Format Radar Cuaca Menggunakan Wradlib Berbasis Python Multi Weather Radar Format Data Processing Using Python-Based," vol. 1, pp. 157-164, 2016.

[3] M. dan B. meteorologi klimatologi dan geofisika RI, "CETAK BIRU (BLUE PRINT) TEKNOLOGI INFORMASI BADAN; KLIMATOLOGI; DAN GEOFISIKA TAHUN 2015-2019,” 2012.

[4] C. on W. R. T. B. NEXRAD, Weather Radar Technology Beyond NEXRAD. National Academy Press, 2002.

[5] A. Huuskonen, E. Saltikoff, and I. Holleman, "The operational weather radar network in Europe," Bull. Am. Meteorol. Soc., vol. 95, no. 6, pp. 897-907, 2014.

[6] W. M. Organization, "Training Workshop on Agricultural," Subj. Final Rep. WMO/ ASEAN Train. Work. Weather Radar Qual. Stand. Bangkok, Thailand, 5-13 Febr. 2018, 2018

[7] Turkish State Meteorological Service, “Training Course on Weather Radar Systems,” no. September, p. $55,2005$.

[8] E. Observing, S. Division, T. State, M. Service, W. M. O. Rmtc-turkey, and A. Facilities, "Training Course on Weather Radar Systems Module D : Radar Products and Operational Applications Module a : Introduction To Radar Module B : Radar Hardware Module C : Processing Basics in Doppler Module D : Radar Products and Module E : Radar Maintenance a," no. September, pp. 0-57, 2005.

[9] C. W. Radar, P. Brochure, and P. Brochure, "Rainscanner Compact Weather Radar."

[10] R. Boudjemaa and D. Oliva, “A multi-objective approach to weather radar network architecture," Soft Comput., vol. 23, no. 12, pp. 42214238, 2019.

[11]BMKG, "Pengindraan Jauh Citra Radar Citra Radar Cuaca Mozaic Indonesia Terkini,” 2019.

[12] BMKG, "Citra Satelit," 2019. 